\title{
Confirmation and Community
}

\section{The Relationships between Teacher Confirmation, Classroom Community, Student}

\author{
Motivation, and Learning
}

\author{
Chad Edwards - Western Michigan University \\ Autumn Edwards - Western Michigan University \\ Amanda Torrens - Ohio University \\ Angela Beck - Western Michigan University
}

\begin{abstract}
The purpose of this study is to examine sense of classroom community as a potential mediating variable in the model of teacher communicative behaviors (teacher confirmation) to the positive student outcomes of student motivation and affective learning. Two competing models were tested for model fit: the linear-sequential model and the partial-mediator model. Results indicated that while both models achieved adequate fit, the linear-sequential model is best suited for the data and for heuristic purposes. Results are discussed in terms of the general model of instructional communication (McCroskey, Valencic, \& Richmond, 2004) and ways to use instructor communicative behaviors to improve the sense of classroom community.
\end{abstract}

Keywords: teacher confirmation, affective learning, student motivation, sense of community 


\section{The Relationships between Teacher Confirmation, Classroom Community, Student Motivation, and Learning}

Research has consistently demonstrated that the interpersonal relationship between instructor and student is of utmost importance for positive development in the classroom. When there are positive relationships between instructors and students, students demonstrate higher levels of motivation and learning (Frymier \& Houser, 2000). The construct of teacher confirmation has been shown to be a strong predictor of positive relational features of instructor and student interactions and positive educational outcomes for students. Teacher confirmation is "the transactional process by which teachers communicate to students that they are endorsed, recognized, and acknowledged as valuable, significant individuals" (Ellis, 2000, p. 266). Almost all studies to date have examined the direct or mediated effects of teacher confirmation on specific student educational outcomes. What is missing is attention to how teacher confirmation might contribute to a relational environment in the classroom. Previous research has demonstrated that by modeling certain behaviors, such as nonverbal immediacy, instructors can play an important role in fostering certain types of learning environments and classroom climates (e.g., Johnson, 2009; Sidelinger \& Booth-Butterfield, 2010). The purpose of this study is to examine sense of classroom community as a potential mediating variable in the model of teacher confirmation to the positive student outcomes of student motivation and affective learning.

\section{Literature Review}

References to a "sense of community" are prevalent in our everyday conversations and in media editorials of current social issues and events. As Pretty, Conroy, Dugay, Fowler, Williams (1996) note, the lack of a sense of community is one potential reason for the increase of urban violence, and its presence is often recognized in the support others provide in times of need. "Beginning with Sarason (1974), who asserted its importance to our wellbeing as individuals and as a society, investigators have accumulated empirical support for the value we intuitively place on sense of community" (Pretty et al., 1996, p. 366). The construct of sense of community has been and continues to be a pivotal concept in the field of community psychology (Lounsbury \& DeNeui, 1996; Sarason, 1974). 
A sense of community (SOC) refers to a perception of the social and relational environment. This perception need not be found in real experience, but in the feeling that "one is part of the 'common good' which will be accessible should the need arise" (Pretty, et al., 1996, p. 366). SOC is different from the concept of social support, which is an individual perception-level variable of the environment focused on networks or relationships within the larger systems of affiliation (Felton \& Shinn, 1992). According to McMillan and Chavis (1986), defined SOC as "a feeling that members have of belonging and being important to each other, and a shared faith that members' needs will be met by the commitment to be together" (p. 9). Or, as Pretty and colleagues (1996) argued,

Sense of community includes the components of feelings of emotional safety and a sense of membership and identification, where one can have some influence over the community while adhering to the demands of the community. The shared emotional connection one feels reinforces the belief that one will be taken care of by the community. (p. 366)

According to McMillan and Chavis (1986), there are four components of SOC: membership, influence, reinforcement/trade, and shared emotional connection. The following sections will detail these components.

\section{Membership}

The first component of SOC is belonging, or a general feeling of holding membership in a community. In order to experience belongingness, one must feel the emotional safety to share information about one's self, or to be one's self in the community. This emotional safety is made possible by a sense of boundary, which defines the logistical time and place settings for group membership. Furthermore, a community must have discursive boundaries that relate to the subject matter of communication and the group's ways of talking. Discursive boundaries are important because understanding the rules and norms of discourse makes possible the emotional safety to share information about one's self. In addition to emotional safety and boundaries, belongingness requires a general sense, or feeling, of belonging, which incorporates an individual's level of faith that he or she will "fit in." There is an initial leap of courage required for membership in a community and "when we believe we will be welcome, that we fit or belong to a community, we have a stronger attraction to that community" (McMillan, 1996). 
Next comes the community's response to that leap of faith, which McMillian and Chavis (1986) termed "acceptance." Finally, a sense of belonging requires the paying of dues to the community. Paying of dues serves as a test of loyalty and renders a sense of entitlement to the community member. "The rights of the community membership come with the expectation that the community can call on its members to make sacrifices" (McMillian, 1996, p. 318). McMillan (1996) argued that belonging, or membership, might also be termed Spirit, or thought of as the initial "sparks of friendship and connection to others so that we have a setting and an audience to express unique aspects of our personality" (p. 317).

\section{Influence}

The second component of SOC is a sense of influence. This influence is concurrent in that it refers not only to the community's role in influencing its members, but to the role of members in influencing the community (McMillan \& Chavis, 1986). In order to experience a SOC, one must have a sense of one's power to affect the community and a sense of the community's power over one's self. According to McMillan (1996), this dimension might also be conceptualized as trust, because the key element of influence is the development of trust in others. Trust occurs through a community's just use of its authority to solve problems and make decisions and through the order (norms, laws, and authority) it establishes and expectations it sets up.

\section{Reinforcement (or Trade)}

The third component of a SOC is a sense of reinforcement. Belonging (or spirit) and influence (or trust) pave the way for a social economy. As needs are integrated, members find ways to receive benefits from each other and the larger community, which reinforces their senses of belonging and influence. While the earlier dimensions are based on members' perceptions of their similarity with each other, reinforcement is characterized by the appreciation of differences among members of the community. These differences are often used as the basis of complementary need fulfillment.

"A community economy based on shared intimacy, which is implied by the term 'sense of community,' represents a social economy, where the medium of exchange is self-disclosure and the value is on risk involved" (McMillan, 1996, p. 321). 
Community members begin by sharing viewpoints that are similar and move on to communicate criticisms and differences of opinion. At first, trades must be fair, but when members stop keeping score or balancing value and give for the joy and privilege of giving, they reach a fuller potential. As McMillan (1996) noted, "when communities transcend scorekeeping and members enjoy giving for its own sake, communities can be thought of as being in a state of Grace" (p. 322). McMillan (1996) suggests that the property of reinforcement might also be thought of as trade, or a mutual give and take rooted in a social economy.

\section{Shared Emotional Connection in Time and Space (or Art)}

The fourth and final component of a SOC is a sense of shared emotional connection in time/space. A sense of belongingness (or spirit) coupled with respected use of power and authority gives way to a sense of influence (or trust). This creates the basis of a feeling of reinforcement. These combine to create a sense of shared history, or connection in time and space (McMillan \& Chavis, 1986). McMillan (1996) argues that this shared history and emotional connection is akin to art, whose basic formation is experience. Community experiences are often symbolized as art when they honor and value the community's transcendent values and encourage the community to meet its highest and most important ideals. Thus, shared symbols and shared reality take on key roles in contributing to an individual's SOC.

\section{Benefits of a Sense of Community}

Sense of community has been empirically linked to positive outcomes for individuals. For instance, SOC has been shown to be significant in terms of citizens' participation in community events and activities (Chavis \& Wandersman, 1990; Davidson \& Cotter, 1989, 1993); and psychosocial dimensions of their mental health (Davidson \& Cotter, 1991; McCarthy, Pretty \& Catano, 1990; Pretty, McCarthy \& Catano, 1992). Furthermore, SOC has been researched in relation to a variety of contexts, including crime prevention (Levine, 1986), teacher sense of efficacy (Newmann, Rutter, \& Smith, 1989), college residence halls (Pretty, 1990), family experiences (Davison, Cotter, \& Stovall, 1991), student burnout (McCarthy, et al., 1990), workplace attributes (Klein \& D’Aunno, 1986; Pretty \& McCarthy, 1991), subjective well-being (Davidson, et al., 1991), and positive characteristics of residents in city life (Davidson \& Cotter, 1986). 
However, the overwhelming tendency to date has been to treat SOC as emanating from psychological characteristics (Pretty, 1990), environment (Glynn, 1981), or as direct/indirect outcomes of the community environment (Lounsbury \& DeNeui, 1996). Relatively less attention has been devoted to the ways in which the behaviors of a community's leaders, guides, or facilitators may contribute to members' levels of SOC. SOC might also fruitfully be studied as an outcome of particular communicative behaviors. The following sections will build this argument.

\section{Community in the Classroom}

John Dewey (1916/1966) first applied the concept of community to education (Solomon, Battistich, \& Hom, 1996). Dewey argued that a sense of community in educational environment is important to foster students' skills and interest, collaborative decision-making and deliberation, and the commitment to democratic values. In general, community describes aspects of social settings that fulfill individuals' needs for connection and belonging (MacIntyre, 1981; McMillan \& Chavis, 1986; Morgan, 1943).

Higher education has long been a site for the study of community (Spitzberg \& Thorndike, 1992). Scholarship on the importance of applying the concept of community to education abounds (e.g., Chaskin \& Rauner, 1995; Hallinger \& Murphy, 1986; Lightfoot, 1983; Noddings, 1992; Sergiovanni, 1992). Research examining community in education has taken two general paths. One avenue has been the examination of how sociological/organizational approaches in educational systems can foster community (Bryk \& Driscoll, 1988). Largely, this approach has focused on administrative or curriculum level decisions in education (e. g., the development of learning communities). The second avenue of research has focused on students' SOC in relation to their learning institutions or classrooms.

In the classroom context, community is a both a feeling of connectedness among classmates and a commonality of learning goals (Rovai, 2002a). Rovai (2002b) maintained that classroom community is robust when students feel connected to each other and their instructor, enact communicative behaviors that increase immediacy, engage in multifaceted interaction, and view themselves as a "social community of learners who share knowledge, 
values, and goals" (p. 322). As such, it is important to examine the ways in which instructor communication might foster a greater sense of classroom community.

The benefits of a strong sense of classroom community are numerous. Student sense of classroom community is positively related to life-long learning (Cross, 1998) and open and friendly communicator styles (Rovai, 2003), and negatively related to student burnout (McCarthy, et al., 1990) and feelings of isolation (Haythornthwaite, Kazmer, Robins, \& Shoemaker, 2000). Johnson's (2009) research indicated that student perceptions of a connected classroom climate are related to higher levels of affective learning. Classroom motivation and academic self-efficacy seem to be the byproducts of a sense of belonging among college first-year students (Freeman, Anderman \& Jensen, 2007).

McKinney, McKinney, Franiuk, and Schweitzer (2006) explored the college classroom and found that sense of classroom community was a significant predictor of students' perceptions of learning, attitudes, and overall course performance. Connection, participation, safety, support, belonging, and empowerment were essential elements of a sense of classroom community leading to positive student educational outcomes. McKinney et al., (2006) further argued that instructor behaviors might help cultivate sense of classroom community and that these efforts might positively impact achievement. Research has demonstrated that when instructors engage students in a positive manner, students have higher levels of learning (Astin, 1993; Tinto, 1987). Additionally, instructor supportiveness and positive relationships with students are important to create a sense of classroom community (McLaughlin, Talbert, Kahne \& Powell, 1990; Schwartz, Merton, \& Bursik, 1987). Larrivee (2000) argued that respect, authenticity, thoughtfulness, and emotional integrity on the part of the instructor were central to creating classroom community. Clearly, the instructor plays an important role in fostering a sense of classroom community. Creating supportive, engaging, authentic, and nurturing relationships is the chief function of the instructional communication construct of teacher confirmation.

\section{Teacher Confirmation}

Martin Buber (1957) was one of the first to argue that confirming communication was an important feature of positive interpersonal relationships. He maintained that confirmation is 
how humans uncover and create social identities in their relationships and with the world around them. Watzlawick, Bavelas, and Jackson (1967) stated that confirmation is the "greatest single factor ensuring mental development and stability" (p. 84). Others have maintained that confirmation is the basic recognition of the existence of others to acknowledge their self-worth and their experiences (Cissna \& Sieburg, 1981). In other words, confirming messages and behaviors "endorse" and "acknowledge" others as having selfworth and being valuable. On the other end of the spectrum, disconfirming communication behaviors demonstrate the neglect of another person's experiences and self-worth. In short, disconfirming communication simply treats another person as insignificant and merely an object. According to Cissna and Sieburg (1981), disconfirmation is the indifference, imperviousness, and disqualification of the person or message.

Although confirming behaviors have been examined in family and interpersonal contexts for the last 40 years, only in the last decade has there been any attention given to this construct in instructional communication literature. Ellis's work $(2000,2004)$ has indentified three behavioral dimensions of teacher confirmation. First, instructors can confirm students by responding to student questions in a way that communicates interest in the students' comments and concerns. Second, instructors can confirm students by demonstrating a general interest in their education and learning. Third, instructors can confirm students by using a teaching style that uses a variety of instructional techniques to help students learn in the classroom.

Schrodt and colleagues have further explored the construct of perceived teacher confirmation. Schrodt, Turman and Soliz (2006) found that perceived teacher confirmation increased students' perceived understanding from an instructor and that this led to higher student evaluations of the teacher and higher levels of perceived instructor credibility. In their model, students' perceived understanding served as a partial mediator. Teacher confirmation has been positivity related to the perceived use of reward, expert and referent power in the classroom (Turman \& Schrodt, 2006). Schrodt et al. (2009) argued that instructor credibility was a partial mediator between prosocial communication behaviors (teacher confirmation, teacher clarity, and nonverbal immediacy) and student learning outcomes with teacher 
confirmation holding the strongest relationship among the three prosocial communication behaviors.

Research has demonstrated that perceived teacher confirmation is positively related with student affective learning with indirect effects for student motivation to learn and cognitive learning (Ellis, 2000). Additionally, perceived teacher confirmation was negatively related to student receiver apprehension (Ellis, 2004). Sidelinger and Booth-Butterfield (2010) found that a distinct but related construct of student-to-student connectedness was an important mediator between perceptions of teacher confirmation and student willingness to talk in class. Teacher confirmation may foster a stronger sense of classroom community that motivates students to learn and leads to higher levels of affective learning.

\section{Student State Motivation to Learn}

Brophy (1987) maintained that student motivation was the "tendency to find academic activities meaningful and worthwhile" (p. 205). State motivation refers to an individual's level of motivation to complete a specific task (Frymier \& Shulman, 1995). In the classroom environment, state motivation "refers to a specific learning situation such as a particular class, task, or content area" (Myers \& Rocca, 2000, p. 291). Student state motivation has been positively related to student learning (Christophel, 1990), perceptions of teacher confirmation (Ellis, 2000), and speaking competence (Carrell \& Menzell, 1997). Additionally, student state motivation has been positively related to immediacy behaviors (Allen, Witt, \& Wheeless, 2006; Kerssen-Griep, 2001), instructor predictability (Avtgis, 2001), and perceptions of instructor fairness (Chory-Assad, 2002). Moreover, student motivation has been negatively associated with instructor verbal aggression (Myers, 2002) and perceived instructor misbehaviors (Wanzer \& McCroskey, 1998).

\section{Affective Learning}

Kearney (1994) defined affective learning as "an increasing internalization of positive attitudes toward the content or subject matter" (p. 81). Several studies have demonstrated an important relationship between student motivation and affective learning (Christensen \& Menzel, 1998; Christophel, 1990; Frymier, 1994; Frymier \& Houser, 2000). Ellis (2000, 2004) argued that affective learning stems from a student's level of state motivation to learn 
and that motivation leads to cognitive learning. Moreover, Rodriguez, Plax, and Kearney (1996) concurred that affective learning may serve as a precursor to cognitive learning. Affective learning has been positively related to instructor specific communication behaviors such as instructor clarity (Avtgis, 2001; Chesebro \& McCroskey, 2001), immediacy (Comstock, Rowel, \& Bowers, 1995; Pogue \& AhYun, 2006; Witt \& Schrodt, 2006), and use of instructor humor (Gorham \& Christophel, 1990). Myers (2002) and Myers and Knox (2000) have shown a negative relationship between affective learning and instructor verbal aggressiveness.

\section{Theoretical Models}

The general relationship from teacher confirmation to student motivation to affective learning is well documented (Ellis, 2000, 2004). What is left out of these models is how students' senses of classroom community may mediate between teacher confirmation and those positive student outcomes. Previous research demonstrates that community and connectedness can lead to student motivation (Freeman et al., 2007) and affective learning (Johnson, 2009). An instructor's modeling of confirming communicative behaviors should produce a heightened sense of classroom community, which, in turn, should lead to greater student motivation and affective learning. The purpose of the current study is to investigate two competing models of a sense of classroom community as a potential mediator of perceived teacher confirmation and student motivation and learning.

The first model, the linear-sequential model, posits that teacher confirmation leads to a student's sense of classroom community which in turn leads to higher levels of motivation to learn and affective learning. In this model, a SOC in the classroom is a full mediator between teacher confirmation and educational outcomes. The second model, the partial-mediator model, hypothesizes that a student's sense of classroom community partially mediates the role between perceptions of teacher confirmation and student motivation to learn and affective learning. In other words, teacher confirmation will also have direct paths to educational outcomes. See Figure 1 and Figure 2 for representations of these competing models. 


\section{Method}

\section{Participants}

The convenience sample was composed of 266 undergraduate students enrolled in introductory communication courses at a large Midwestern university. Participants included 178 females (66.9\%), and 88 males (33.1\%). The majority of participants self-identified as Caucasian/White $(79.32 \%, n=211)$. Participants' ages ranged from 18 to 41 years, with a mean of $20.79(S D=3.03)$. The largest percentage of participants classified as juniors (34.2\%, $n=91)$, followed by first-years $(24.1 \%, n=64)$, sophomores $(21.4 \%, n=57)$, seniors $(18.0 \%, n=48)$ and "others" $(1.9 \%, n=5)$. Participants received extra credit points in return for taking part in the study. The study was given to participants in the 13th week of the semester to allow for firm perceptions of the instructors and classes to emerge.

\section{Procedures}

Participants were asked to complete a questionnaire that contained four measures and a small demographic section. Following the procedures of Plax, Kearney, McCroskey, and Richmond (1986), participants were asked to complete the questionnaire while referencing "the instructor you have in the course which meets prior to this class." This procedure has been utilized successfully in previous research (e. g., Christophel, 1990; Myers \& Rocca, 2000; Schrodt, et al., 2006). After completion of the questionnaire, participants were thanked and debriefed.

\section{Instruments}

Ellis's (2000) Teacher Confirmation Scale is a 16-item instrument designed to assess the extent to which instructors exhibit confirming behaviors. Items are measured using a 5-point scale ranging from 1 (strongly disagree) to 5 (strongly agree) across three dimensions: (1) instructor's response to questions (5 items; e. g., "My instructor indicates that $\mathrm{s} / \mathrm{he}$ appreciates students' questions or comments."), (2) instructor's interest in students and their learning (6 items; e. g., "My instructor communicates that $\mathrm{s} / \mathrm{he}$ is interested in whether students are learning."), and (3) instructor's style of teaching (5 items; e. g., "My instructor uses an interactive teaching style."). Previous studies have demonstrated good subscale reliabilities ranging from .83 to .87 (Ellis, 2000, 2004; Schrodt et al., 2006). In the current study, the subscales produced acceptable reliabilities with coefficients of .84 for instructor's 
response to questions $(M=4.15, S D=.79), .83$ for instructor's interest in students and their learning $(M=4.07, S D=.78)$, and .81 for instructor's teaching style $(M=3.59, S D=.95)$.

In order to measure students' senses of classroom community, a modified version of Lounsbury and DeNeui's (1996) Collegiate Psychological Sense of Community (CPSOC) was employed. CPSOC is a unidimensional 14-item measure designed to assess a student's subjective sense connection to her or his university or college. Items are measured using a 5point scale ranging from 1 (strongly disagree) to 5 (strongly agree) (e. g., "There is a real sense of community here."). For the present study, some items were modified to reflect a subjective sense of community for the target class. For example, the original item of "I feel very attached to this college" was altered to "I feel very attached to this class." A similar modification based on type of environment has been advanced in the literature (Lounsbury, Loveland, \& Gibson, 2003). Previous reliabilities for the scale have ranged from .88 to .90 (Lounsbury \& DeNeui, 1996). The modified version in the current scale achieved an excellent reliability coefficient of $.95(M=3.20, S D=.94)$.

Christophel's (1990) Student Motivation Scale is a 12-item instrument designed to assess students' motivation to learn from a target instructor in a specific course. Items are rated along 7-point semantic differential scales (e.g., "motivated/unmotivated," "involved/uninvolved"). Past studies have reported reliability coefficients consistently higher than .90 (Christophel, 1990; Myers, 2002). A reliability coefficient of $.95(M=4.84, S D=$ 1.40) was obtained in the current study.

McCroskey's (1994) Affective Learning Measure is an 8-item instrument designed to measure a student's affect for course subject matter along a series of semantic differential scales (7-point). The first four items address affect toward the course content (e.g., "I feel that the class content is: valuable/worthless"), while the last four items address affect toward other classes in the content area (e.g., "My likelihood of taking future courses in this content area is: improbable/probable"). Previous studies have demonstrated reliability coefficients exceeding .90 (McCroskey, 1994; Edwards, Edwards, Qing, \& Wahl, 2007). For the current study, a reliability coefficient of $.94(M=5.32 ; S D=1.53)$ was obtained for affective learning. 


\section{Results}

\section{Measurement Model Analysis}

Using Kline's (2005) two-step modeling procedures, the measurement model and hypothesized models were estimated with Maximum Likelihood estimation using AMOS 18.0. Because of the moderate sample size, Tucker-Lewis Index (TLI), Comparative Fit Index (CFI), goodness-of-fit index (GFI), and the root mean square error of approximation (RMSEA) were utilized to assess model fit. All values were standardized prior to assessment of model fit. Values larger than .90 for the TLI, CFI, and GFI, and values lower .10 for the RMSEA indicated acceptable model fit (Kline, 2005).

A confirmatory factor analysis of the measurement model was utilized to examine the relationship between indicators and latent constructs before testing the two hypothesized models. Three dimensions signify the latent construct of perceived teacher confirmation: responding to questions, demonstrating interest, and teaching style. Because sense of classroom community, student state motivation, and student affective learning are measured unidimensionally, items for each measure were parceled into three indicators for each construct (MacCallum \& Austin, 2000). For example, three parcels (a sum of randomly chosen items from the CSOCC scale) represent sense of classroom community. Because the number of items on the CSOCC is not evenly divisible by three, each sum was divided by the number of items in the parcel. Better psychometric properties, which can lead to more parsimonious models, are the advantages of using parcels for latent variables instead of indicators only (Little, Cunningham, Shahar, \& Widaman, 2002; MacCallum \& Austin, 2000).

The measurement model demonstrated acceptable goodness of fit, $\chi^{2}(N=252,48)=111.05$, $p<.001 ; \mathrm{TLI}=.98 ; \mathrm{CFI}=.98 ; \mathrm{GFI}=.93 ; \mathrm{RMSEA}=.072$. Examination of the modification indices suggested no changes to the measurement model that would significantly enhance model fit. The measurement model with loadings for the indicators and residuals variables is shown in Figure 3. 


\section{Model Analysis}

The purpose of the current study was to test the hypothesized model of perceived teacher confirmation, student motivation, and affective learning to investigate the potential role of a student's sense of community with the classroom environment. The linear-sequential model demonstrated good model fit, $\chi^{2}(N=252,51)=115.55, p<.001$; TLI $=.98$; CFI $=.98$; GFI $=.93$; RMSEA $=.071$. Another model, using student sense of community as a partialmediator between teacher confirmation, student motivation and affective learning, was also tested. This model also achieved good model fit, $\chi^{2}(N=252,48)=111.05, p<.001$; TLI $=$ $.98 ; \mathrm{CFI}=.98 ; \mathrm{GFI}=.93 ; \mathrm{RMSEA}=.072$. Because of the linear sequential model was nested in the full mediator model, a statistical comparison of the two models was performed. There was not a significant decline in model fit, $\Delta \chi^{2}(N=252,3)=4.48, p>.05$ between the linear sequential model and the mediator model. However, two paths were not significant in the full mediator model (sense of community to affective learning and teacher confirmation to affective learning). Additionally, the path from teacher confirmation to student motivation was at the $p=.05$ level. When these paths are removed, the linear model is the result. In other words, while both models achieved good model fit, the linear sequential model is the more parsimonious model in terms of significant pathways. Student sense of classroom community in the linear-sequential model accounted for considerable variance in both student motivation $\left(R^{2}=.70\right)$ and affective learning $\left(R^{2}=.80\right)$. Figure 4 shows pathways with significant paths indicated.

\section{Discussion}

The purpose of the current study was to examine the role of sense of classroom community in mediating the relationship between perceived teacher confirmation and student levels of motivation and affective learning. Results indicated that the linear-sequential model was best suited for the data, insofar as perceived teacher confirmation had a direct significant path to student sense of classroom community, which had a direct significant path to student motivation, which had a direct significant path to affective learning.

Although the competing partial-mediator model achieved acceptable model fit, it was not significantly different from the linear-sequential model and several important paths were not statistically significant. When these paths are removed from the model, the essential result is 
the linear-sequential model. In other words, the linear-sequential model provides the most parsimonious explanation of paths among perceived teacher confirmation, sense of classroom community, and student educational outcomes. Additionally, this model provides a clearer heuristic for instructors wanting to use confirmation behaviors to increase a sense of community in the classroom.

McCroskey, Valencic, and Richmond's (2004) general model of instructional communication posits that an instructor's verbal and nonverbal communication behaviors (e.g., perceived teacher confirmation) lead to student perceptions of the instructor that in turn influence instructional outcomes (e.g., student motivation and affective learning).

Taken alongside other recent research that examines the role of relational environment variables in mediating the effects of instructor communication on educational aims, results of the current study suggest that McCroskey et al.'s (2004) general model may be productively expanded to acknowledge that instructor communication leads to student perceptions of both instructor and relational environment, which then lead to instructional outcomes.

Ellis $(2000,2004)$ maintained that teacher confirmation is an important variable in creating a positive instructor/student climate. The current results extend previous work on teacher confirmation (Ellis, 2000, 2004; Schrodt et al., 2006, 2009) by showing that perceived positive confirming behaviors on the part of the instructor foster a stronger relationship in the classroom in the form of a stronger sense of community among students.

The current study also supports Rovai's (2003) finding that open communication and friendly communication styles help foster feelings of connectedness in the classroom. When teachers engage in confirming behaviors, students are more likely to feel at ease with the classroom environment and perceived a greater sense of connectedness and belonging. This greater sense of connectedness and belonging is a strong indicator of membership in a community (McMillan \& Chavis, 1986). In another study, two confirming behaviors of instructor encouragement of student participation and "warm" interactions produced higher levels of student feelings of belonging (Freeman, et al., 2007). Sidelinger and Booth-Butterfield (2010) found that teacher confirmation was associated with a supportive connected classroom 
climate (focusing on student-to-student communication). The current study extends these findings by demonstrating that the larger construct of sense of classroom community mediates the role of perceived teacher confirmation to motivation and affective learning.

Additionally, the direct path from sense of classroom community to motivation has support in the community literature. Freeman, et al. (2007) found that there was a strong relationship between a student's sense of belonging (a construct related to sense of community) and motivational aspects related to learning in college. These types of findings are also supported with younger populations of students (Anderman \& Anderman, 1999; Goodenow, 1993a, 1993b). While not tested in the current design, it seems plausible that one reason for increased levels of student motivation when sense of community is strong is the idea that members of the community hold each other accountable for their own actions (McMillan \& Chavis, 1986). In other words, students might feel a community pressure to do well in the course as to not let the classroom community down.

\section{Limitations and Future Research}

There are a few limitations to the current study that need to be addressed. First, because the study did not employ an experimental design manipulating levels of instructor confirmation, any causal claims are inferred from theoretical assumptions rather than empirical validation. Second, a halo effect might occur when students are asked to report on perceptions of their instructors' behaviors (Hess, Smythe, \& Communication 451, 2001). In other words, a general positive or negative affect for the instructor, classroom, or even the course might adversely impact how students rate teacher confirmation and/or their own sense of classroom community. Future research should seek to isolate features of the classroom environment (e.g., class size, type of course, instructional style) that might impact both a sense of classroom community and perceived teacher confirmation.

\section{Conclusions}

The current study sought to examine the role that student sense of classroom community has in mediating the relationship between perceived teacher confirmation and educational outcomes. The results suggested that a sense of classroom community is an important feature that instructional communication scholars should address when trying to understand the 
relationships between instructor behaviors and learning outcomes. Students who feel a strong sense of community report greater levels of motivation to learn which leads to higher levels of affective learning. Teacher confirming behaviors can help this process happen by providing a warm, caring, and supportive classroom environment for student community to grow and flourish. 


\section{References}

Allen, M., Witt, P. L., \& Wheeless, L. R. (2006). The role of teacher immediacy as a motivational factor in student learning: Using meta-analysis to test a causal model. Communication Education, 55, 21-31.

Anderman, L. H., \& Anderman, E. M. (1999). Social predictors of changes in students' achievement goal orientations. Contemporary Educational Psychology, 25, 21-37.

Astin, A. (1993). What matters in college: Four critical years revisited. San Francisco: Jossey-Bass.

Avtgis, T. A. (2001). Affective learning, teacher clarity, and student motivation as a function of attributional confidence. Communication Research Reports, 18, 345-353.

Brophy, J. (1987). Synthesis of research on strategies for motivating students to learn. Educational Leadership, 45, 40-48.

Bryk, A. \& Driscoll, M. (1988). The high school as community: Contextual influencesand consequences for students and teachers. Madison: University of Wisconsin, National Center on Effective Secondary Schools.

Buber, M. (1957). Distance and relation. Psychiatry, 20, 97-104.

Carrell, L. J., \& Menzel, K. E. (1997). The impact of preparation and motivation on learning performance. Communication Education, 46, 262-272.

Chaskin, R., \& D. Rauner. D. (1995). Youth and caring: An introduction.Phi Delta Kappan, $76,667-74$.

Chavis, D. \& Wandersman, A. (1990). Sense of community in the urban environment: A catalyst for participation and community development. American Journal of Community Psychology, 18, 55-81.

Chesebro, J. L., \& McCroskey, J. C. (2001). The relationship of teacher clarity and immediacy with student state receiver apprehension, affect, and cognitive learning. Communication Education, 50, 59-68.

Chory-Assad, R. M. (2002). Classroom justice: Perceptions of fairness as a predictor of student motivation, learning, and aggression. Communication Quarterly, 50, 58-77.

Christensen, L. J., \& Menzel, K. E. (1998). The linear relationship between student reports of teacher immediacy behaviors and perceptions of state motivation, and of cognitive, affective, and behavioral learning. Communication Education, 47, 82-90. 
Christophel, D. (1990). The relationships among teacher immediacy behaviors, student motivation and learning. Communication Education, 39, 323-340.

Cross, K. P. (1998, July/August). Why learning communities? Why now? About Campus, 411.

Cissna, K. N. L., \& Sieburg, E. (1981). Patterns of interactional confirmation and disconfirmation. In C. Wilder-Mott \& J. H. Weakland (Eds.), Rigor and imagination: Essays from the legacy of Gregory Bateson (pp. 253-282). New York: Praeger.

Comstock, J., Rowell, E., \& Bowers, J. W. (1995). Food for thought: Teacher nonverbal immediacy, student learning and curvilinearity. Communication Education, 44, 251266.

Davidson, W., \& Cotter, P. (1986). Measurement of sense of community within the sphere of city. Journal of Applied Social Psychology, 16, 608-619.

Davidson, W., \& Cotter, P. (1989). Sense of community and political participation. Journal of Community Psychology, 17, 119-125.

Davidson, W., \& Cotter, P. (1991). The relationship between sense of community and subjective well-being: A first look. Journal of Community Psychology, 18, 246-253.

Davidson, W., \& Cotter, P. (1993). Psychological sense of community and support for public school taxes. American Journal of Community Psychology, 21, 59-66.

Davidson, W., Cotter, P. R. \& Stovall, J. G. (1991). Social predispositions for the development of sense of community. Psychological Reports, 68, 817-818.

Dewey, J. (1916/1966). Democracy and education. New York: MacMillian.

Edwards, C., Edwards, A., Qing, Q., \& Wahl, S. T. (2007). The influence of computermediated word-of-mouth communication on student perceptions of instructor and attitudes toward learning course content. Communication Education, 56, 255-277.

Ellis, K. (2000). Perceived teacher confirmation: The development and validation of an instrument and two studies of the relationship to cognitive and affective learning. Human Communication Research, 26, 264-291. doi:10.1093/hcr/26.2.264

Ellis, K. (2004). The impact of perceived teacher confirmation on receiver apprehension, motivation, and learning. Communication Education, 53,1-20. doi:10.1080/0363452032000135742

Felton, B., \& Shinn, M. (1992). Social integration and social support: Moving social support beyond the individual level. Journal of Community Psychology, 20, 103-115. 
Freeman, T. M., Anderman, L. H., \& Jensen, J. M. (2007). Sense of belonging in college freshmen at the classroom and campus levels. Journal of Experimental Education, 75, 203-220.

Frymier, A.B. (1994). A model of immediacy in the classroom. Communication Quarterly, $42,133-144$.

Frymier, A.B., \& Houser, M. L. (2000). The teacher-student relationship as an interpersonal relationship. Communication Education, 49, 207-219.

Frymier, A.B., \& Shulman, G.M. (1995). "What's in it for me?": Increasing content relevance to enhance students' motivation. Communication Education, 44, 40-50.

Glynn, T. J. (1981). Psychological sense of community: Measurement and application. Human Relations, 34, 780-818.

Goodenow, C. (1993a). Classroom belonging among early adolescent students: Relationships to motivation and achievement. Journal of Early Adolescence, 13, 21-43.

Goodenow, C. (1993b). The psychological sense of school membership among adolescents: Scale development and educational correlates. Psychology in the Schools, 30, 79-90.

Gorham, J., \& Christophel, D. M. (1990). The relationship of teachers' use of humor in the classroom to immediacy and student learning. Communication Education, 30, 4662.

Hallinger, P., \& Murphy, J. (1986). The social context of effective schools. American Journal of Education, 94, 328-355.

Haythornthwaite, C., Kazmer, M., Robins, J., \& Shoemaker, S. (2000). Making connections: Community among computer-supported distance learners. Paper presented at the Association for Library and Information Science Education 2000 Conference. San Antonio, Texas.

Hess, J. A., Smythe, M. J., \& Communication 451. (2001). Is teacher immediacy actually related to student cognitive learning? Communication Studies, 52, 197-219.

Johnson, D. I. (2009). Connected classroom climate: A validity study. Communication Research Reports, 26, pp. 146-157

Kearney, P. (1994). Affective learning. In R. B. Rubin, P. Palmgreen, \& H. E. Sypher (Eds.), Communication research measures: A sourcebook (pp. 81-85). New York: Guilford Press. 
Kerssen-Griep, J. (2001). Teacher communication activities relevant to student motivation: Classroom facework and instructional communication competence. Communication Education, 50, 256-273.

Klein, K., \& D'Aunno, T. (1986). Psychological sense of community in the workplace. Journal of Community Psychology, 14, 365-377.

Kline, R.B. (2005). Principles and practice of structural equation modeling (2nd ed.). New York: Guilford Press.

Larrivee, B. (2000). Creating caring learning communities. Contemporary Education, 71(2), $18-21$.

Levine, M. D. (1986). Working it out: A community re-creation approach to crime prevention. Journal of Community Psychology, 14, 378-390.

Lightfoot, S. L. (1983). The good high school: Portraits of character and culture. New York: Basic Books.

Little, T. D., Cunningham, W. A., Shahar, G., \& Widaman, K. F. (2002). To parcel or not to parcel: Exploring the question, weighing the merits. Structural Equation Modeling, 9, 151-173.

Lounsbury, J.W., \& DeNeui, D. (1996). Collegiate psychological sense of community inrelation to size of college/university and extroversion. Journal of CommunityPsychology, 24, 381-395.

Lounsbury, J. W., Loveland, J. L., \& Gibson, L. W. (2003). An investigation of Big Five personality traits in relation to psychological sense of community. Journal of Community Psychology, 31, 531-541.

MacCallum, R. C., \& Austin, J. T. (2000) Applications of structural equation modeling in psychological research. Annual Review of Psychology, 51, 201-226.

MacIntyre, A. (1981). After virtue. Notre Dame, IN: University of Notre Dame Press.

McCarthy, M., Pretty, G., \& Catano, V. (1990). Psychological sense of community and burn-out. Journal of Community Psychology, 18, 211-216.

McCroskey, J. C. (1994). Assessment of affect toward communication and affect toward instruction in communication. In S. Morreale \& M. Brooks (Eds.), 1994 SCA summer conference proceedings and prepared remarks: Assessing college student competence in speech communication. Annandale, VA: Speech Communication Association. 
McCroskey, J. C., Valencic, K. M., \& Richmond, V. P. (2004). Toward a general modelof instructional communication. Communication Quarterly, 52, 197-210.

McKinney, J. P., McKinney, K. G., Franiuk, R., \& Schweitzer, J. (2006). The college classroom as a community: Impact on student attitudes and learning. College Teaching, 54, 281-284.

McLaughlin, M. W., Talbert, J., Kahne, J., \& Powell, J. (1990). Constructing a personalized school environment. Phi Delta Kappan, 72(3), 230-235.

McMillan, D.W. (1996). Sense of community. Journal of Community Psychology, 24, 315325.

McMillan, D. W., \& Chavis, D. M. (1986). Sense of community: a definition and theory. Journal of Community Psychology, 14(1), 6-23.

Morgan, A. (1943). The small community. New York: Harper.

Myers, S. A., \& Knox, R. L. (2000, April). The relationship between instructor argumentativeness and verbal aggressiveness, and student state motivation, relevance, affective learning, and satisfaction. Paper presented at the meeting of the Central States Communication Association, Detroit, MI.

Myers, S. A. (2002). Perceived aggressive instructor communication and student state motivation, learning, and satisfaction. Communication Reports, 15, 113-121.

Myers, S. A., \& Rocca, K. A. (2000). Students' state motivation and instructors' use of verbally aggressive messages. Psychological Reports, 87, 291-294.

Newmann, F. M., Rutter, R. A., \& Smith, M. S. (1989). Organizational factors that affect school sense of efficacy, community, and expectations. Sociology of Education, 62, 221-238.

Noddings, N. (1992). The challenge to care in schools: An alternative approach to education. New York: Teachers College Press.

Plax, T. G., Kearney, P., McCroskey, J. C., \& Richmond, V. P. (1986). Power in the classroom VI: Verbal control strategies, nonverbal immediacy, and affective learning. Communication Education, 35,43-55.

Pogue, L. L., \& AhYun, K. (2006). The effect of teacher nonverbal immediacy and credibility on student motivation and affective learning. Communication Education, 55, 331-344.

Pretty, G. H. (1990). Relating psychological sense of community to social climate characteristics. Journal of Community Psychology, 18, 60-65. 
Pretty, G. H., \& McCarthy, M. (1991). Exploring psychological sense of community among women and men of the corporation. Journal of Community Psychology, 19, 351-361.

Pretty, G. H., Conroy, C., Dugay, J., Fowler, K., \& Williams, D. (1996). Sense of community and its relevance to adolescents of all ages. Journal of Community

Psychology, 24, 365-379.

Pretty, G.H., McCarthy, M., \& Catano, V. (1992). Psychological environments and burnout: Gender considerations in the corporation. Journal of Organizational Behaviour, 13, 701-711.

Rodriguez, J. I., Plax, T. G., \& Kearney, P. (1996). Clarifying the relationship between teacher nonverbal immediacy and student cognitive learning: Affective learning as the central causal mediator. Communication Education, 45, 293-305.

Rovai, A. P. (2002a). Development of an instrument to measure classroom community. Internet and Higher Education, 5, 197-211.

Rovai, A. P. (2002b). Sense of community, perceived cognitive learning, and persistence in asynchronous learning networks. Internet and Higher Education, 5, 319-332.

Rovai, A. P. (2003). The relationships of communicator style, personality-based learning style, and classroom community among online graduate students. Internet and Higher Education, 6, 347-363.

Sarason, S. (1974). Psychological sense of community. San Francisco: Jossey-Bass.

Schrodt, P., Turman, P.D., \& Soliz, J. (2006). Perceived understanding as a mediator of perceived teacher confirmation and students' ratings of instruction. Communication Education, 55, 370-388. doi:10.1080/03634520600879196

Schrodt, P., Witt, P. L., Turman, P. D., Myers, S. A., Barton, M. H., \& Jernberg, K. A. (2009). Instructor credibility as a mediator of instructors' prosocial communication behaviors and students' learning outcomes. Communication Education, 58 , 350-371.

Schwartz, G., Merten, D., \& Bursik, R, J., Jr. (1987). Teaching styles and performance values in junior high school: The impersonal, nonpersonal, and personal. American Journal of Education, 95, 346-379.

Sergiovanni, T. J. (1992). Moral leadership. San Francisco: Jossey-Bass.

Sidelinger, R., \& Booth-Butterfield, M. (2010). Co-constructing student involvement: An examination of teacher confirmation and student-to-student connectedness in the college classroom. Communication Education, 59, 165-184. 
Solomon, D., Battistich, V., \& Hom, A. (1996). Teacher beliefs and practices in schools serving communities that differ in socioeconomic level. Journal of Experimental Education, 64, 327-347.

Spitzberg, I. J., \& Thorndike V. V. (1992). Creating community on college campuses. Albany: State University of New York Press.

Tinto, V. (1987). Leaving college: Rethinking the causes and cures of student attrition. Chicago: The University of Chicago Press.

Turman, P. D., \& Schrodt, P. (2006). Student perceptions of teacher power as a function of perceived teacher confirmation. Communication Education, 55, 265-279. doi:10.1080/ 03634520600702570

Wanzer, M. B. \& McCroskey, J. C. (1998). Teacher socio-communicative style as a correlate of student affect toward teacher and course material. Communication Education, 47, 43-52.

Watzlawick, P., Bavelas, B. J., Jackson, D. D. (1967). Pragmatics of human communication. A study of interactional patterns, pathologies and paradoxes. New York: W.W. Norton \& Company.

Witt, P. L., \& Schrodt, P. (2006). The influence of instructional technology use and teacher immediacy on student affect for teacher and course. Communication Reports, 19, 115. 


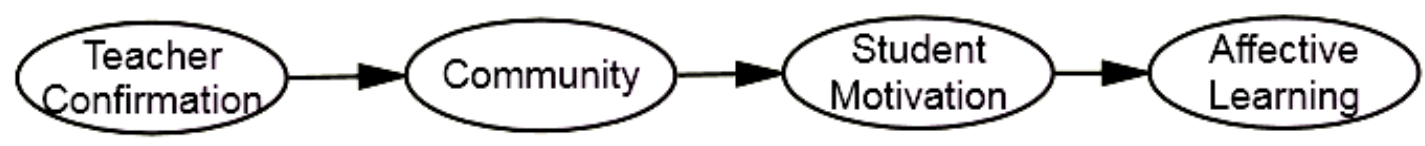

Figure 1. Linear-sequential Model.

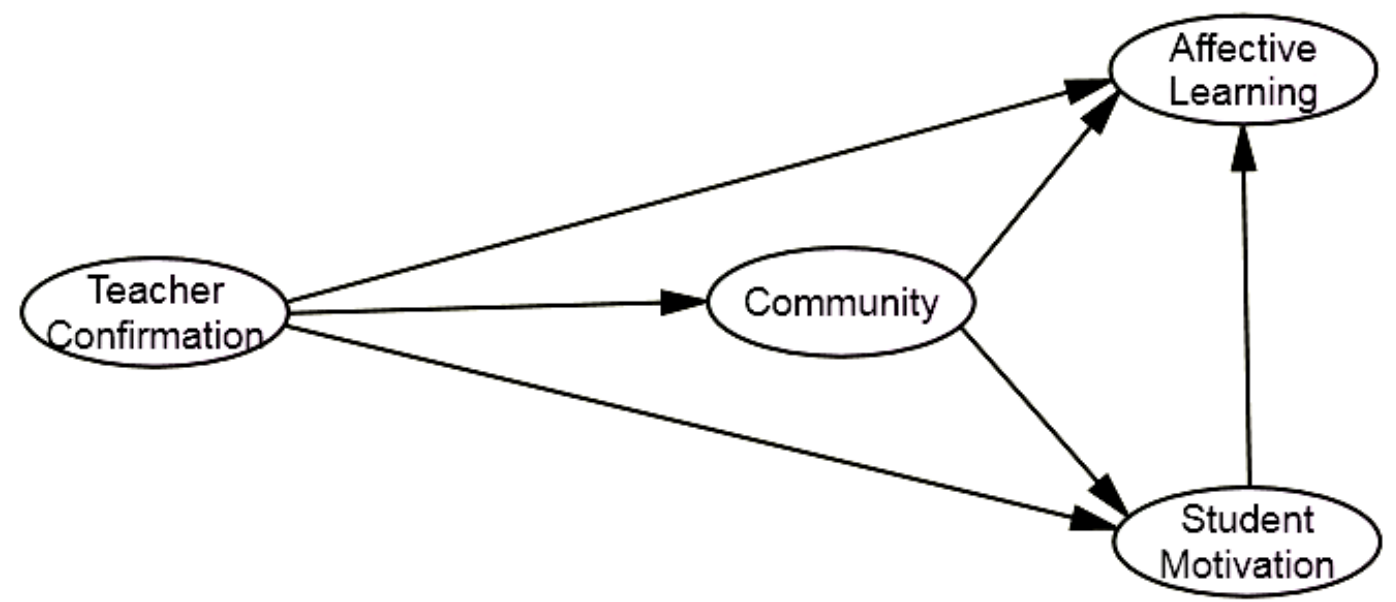

Figure 2. Partial-mediator Model. 


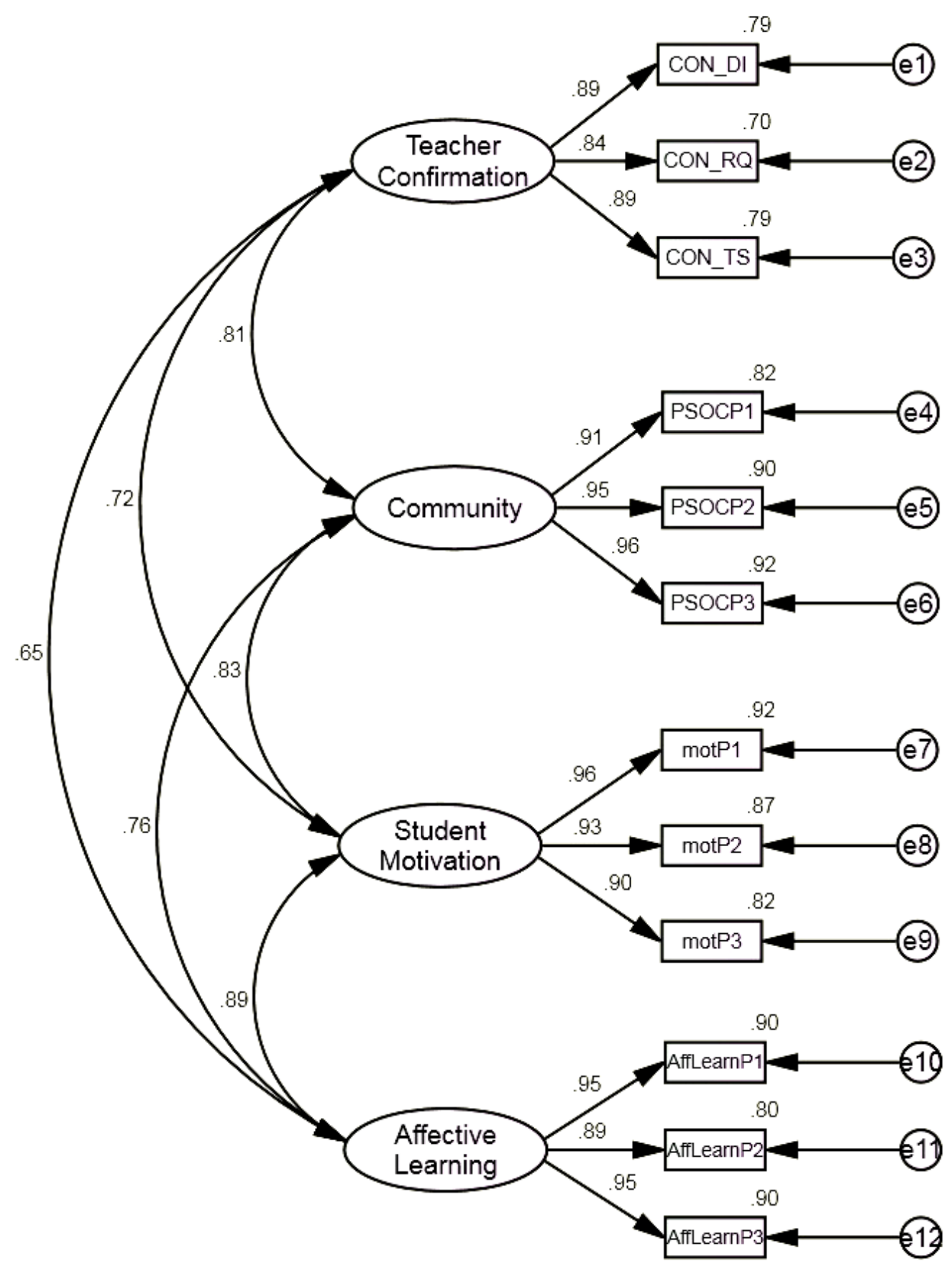

Figure 3. Measurement Model. 


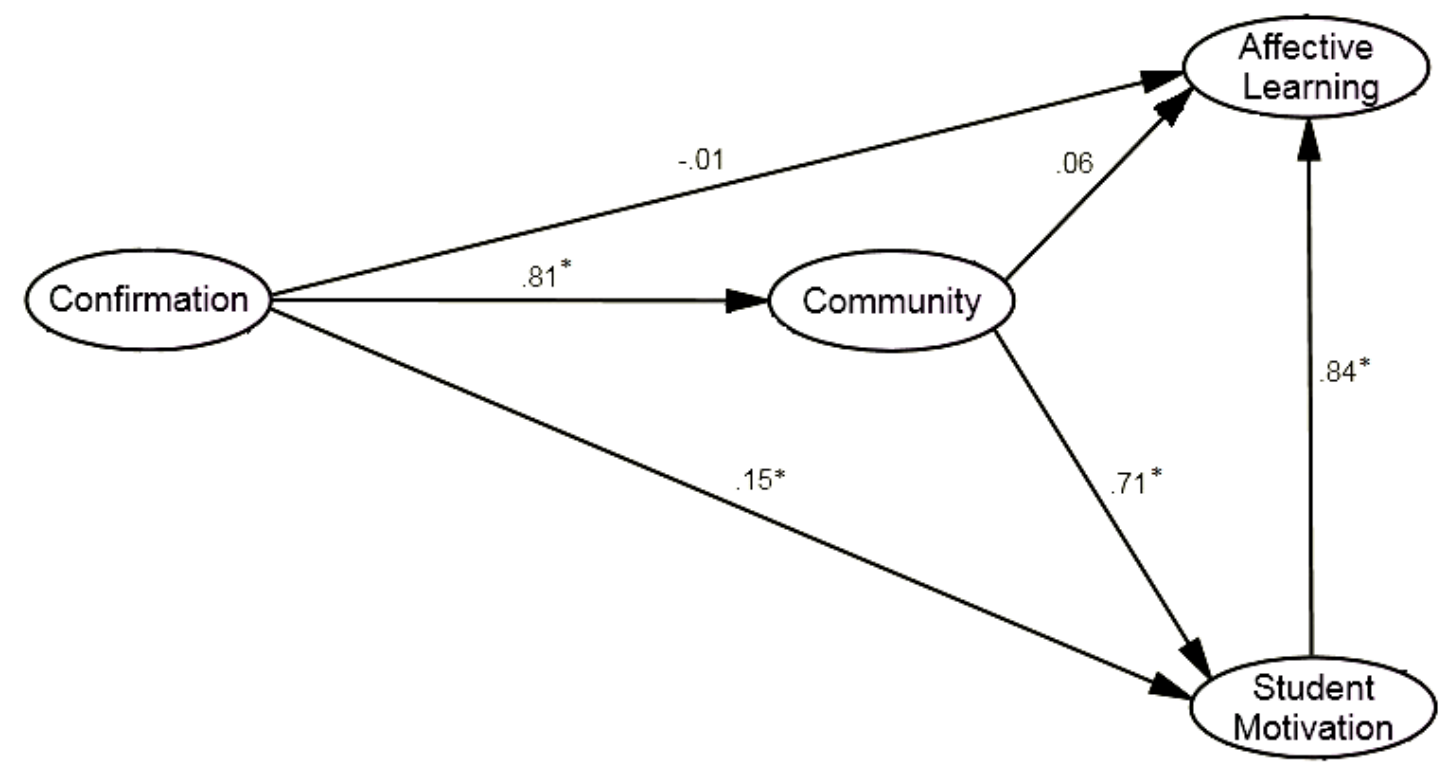

Figure 4. Model with Significant Paths Marked. ${ }^{*} p<.05$ 